\title{
El Banco de Santander, 1857-1934: las particularidades de un banco local
}

\author{
Andrés Hoyo Aparicio \\ Universidad de Cantabria
}

Resumen

Este artículo tiene por objetivo identificar las razones que pueden explicar cómo un modesto banco local, fundado por un grupo de comerciantes que desempeñaban su actividad en el puerto de Santander en los años centrales del siglo XIX, pudo mantenerse en el tiempo hasta, avanzado ya el siglo XX, lograr estar en condiciones de entrar a formar parte en el selecto club de los "siete grandes" de la banca española. Se concluye que fueron los fuertes vínculos familiares y de amistad instrumental entre sus gestores, junto con el diseño de una política financiera con marcada aversión al riesgo, y el talante proteccionista, los que conforman los tres principales rasgos a tener en consideración para explicar el porqué de su longevidad y prolongado acomodo al ámbito de lo local a lo largo del periodo considerado. Estos rasgos caracterizadores empezaron a perfilarse ya en sus orígenes como banco emisor.

Palabras clave

Historia bancaria; Historia financiera; Comerciantes-capitalistas

Códigos JEL: N2, G21, G34, R1
BANCO DE SANTANDER, 1857-1934: THE PECULIARITIES OF A LOCAL BANK

\section{Abstract}

This paper aims to identify the reasons can help us to explain how a modest local bank, founded by a group of merchants that carried out their activity in the port of Santander in the central years of the 19th century, was able to sustain over time until joining the select club of the "big seven" of Spanish banking. It is concluded that three distinctive features should take into account in order to explain its longevity and prolonged accommodation to the local sphere throughout this long period: the strong family ties and instrumental friendship between its managers, the design of a financial policy with marked risk aversion and a protectionist attitude, against all competition. These distinctive features began to emerge in its very origins as an issuing bank.

Keywords

Banking history; Financial history; Merchant-capitalist

JEL codes: N2, G21, G34, R1

Fecha de recepción del original: 11 de diciembre de 2019; versión definitiva: 27 de mayo de 2020.

Andrés Hoyo Aparicio, Departamento de Historia Moderna y Contemporánea, Universidad de Cantabria.

Avenida de los Castros, s/n, 39005- Santander (Cantabria)

E-mail: hoyoa@unican.es, TIf.: +34 942201132; ORCID ID: 0000-0002-5114-8721. 


\section{El Banco de Santander, 1857-1934: las particularidades de un banco local}

Andrés Hoyo Aparicio

Universidad de Cantabria

Los años que transcurrieron entre 1844 y 1874 acotan el periodo de la pluralidad de emisión en España. Antes de esa primera fecha, solo el Banco de San Fernando, creado en 1829, detentaba el derecho exclusivo de emisión. A éste siguieron el Banco de Isabel II (1844), de vida efímera, -terminó fusionándose con el de San Fernando tres años después de su fundación-, y los Bancos de Barcelona (1844) y de Cádiz (1847). Con la llegada de los progresistas al poder, en julio de 1854, se abrió la posibilidad de superar los límites que a la apertura de nuevos establecimientos emisores habían ido imponiendo la Ley de Sociedades Anónimas de 1848 y las leyes bancarias de 1849 y 1851 . En el ánimo de los nuevos legisladores dominó la intención de procurar una más adecuada función movilizadora del ahorro. Este propósito quedó materializado en dos importantes leyes aprobadas en enero de 1856. Una de ellas instauraba nuevas reglas para la fundación sin límites de sociedades de crédito con amplias facultades financieras, que iban más allá de los descuentos y préstamos a corto plazo, salvo la de emitir billetes. La otra ley reservaba esta importante facultad a aquellos bancos que se fueran creando en los lugares en que se pidiera, a razón de uno por plaza. La ley de bancos de emisión de 1856 estableció, así, las bases de un nuevo sistema de emisión fiduciaria en España. El Banco de San Fernando tomó el nombre de Banco de España, y se fijaron las condiciones para atender nuevas peticiones para el establecimiento de bancos emisores. En total se crearon 18 nuevos bancos con capacidad para emitir billetes. Todos ellos se caracterizaron por operar dentro de un ámbito de influencia local; muy pocos establecieron sucursales más allá de la localidad en donde fijaron su domicilio social. En su mayoría fueron pensados como proveedores de medios de pago y como dispensadores de crédito comercial a corto plazo para un entorno territorial reducido. No hubo, por tanto, competencia entre billetes, lo que dio como resultado un sistema emisor de "monopolios yuxtapuestos" (Sudriá, 2016: 162).

El Banco de Santander fue uno de los 20 bancos emisores que llegaron a funcionar. Fundado dentro de la primera gran oleada de apertura de este tipo de establecimientos (18561859), su historia difícilmente puede disociarse de la dinámica de aquella actividad que no solo fue la razón de su fundación, sino que, además, condicionó buena parte de su evolución posterior: el Santander fue el banco del comercio; un banco de comerciantes y para comerciantes, en la que todos los accionistas fundadores guardaron estrechos vínculos de familiaridad y amistad instrumental. Atendiendo al capital societario con el que empezó a funcionar, se trató de un establecimiento de dimensiones más bien modestas si se le compara con los pioneros bancos emisores que operaban en Barcelona y Cádiz en ese mismo momento de su fundación. El millón doscientos cincuenta mil pesetas de capital desembolsado que reflejó su primer balance era, por entonces, un $20 \%$ mayor que con el que inauguraron su actividad los bancos de La Coruña o de Jerez de la Frontera, pero, por citar solo a los que se fundaron dentro de esa primera oleada, sensiblemente inferior a lo que en sus balances contabilizaron los bancos de Sevilla, VaIladolid, Zaragoza y el cercano Banco de Bilbao. Y de modesto también hay que calificar el valor de las cuentas de cartera y préstamos que llegó a gestionar. Tomando como referencia el año 1865, el saldo de poco más de 4,4 millones que contabilizó significaba mucho menos de la mitad que en los bancos de Barcelona, Cádiz o Zaragoza, inferior también a lo registrado en los de Málaga y Sevilla, pero el doble de lo que anotaban los balances de los bancos de La Coruña o de Jerez de la Frontera. Dentro del entorno de la banca de emisión que operaba en la zona nordeste del país, el Banco de Santander tuvo mayor peso financiero que los que se constituyeron en San Sebastián, Vitoria o Pamplona, pero también el valor de su activo fue, por término medio, prácticamente la mitad de lo que en sus balances indicaba el Banco de Bilbao.

El 9 de enero de 1984, los presidentes de los Ilamados "siete grandes" de la banca española se juntaron en un almuerzo privado que tuvo lugar en un restaurante madrileño con el motivo de homenajear al recién jubilado presidente del Banco Español de Crédito, José María Aguirre Gonzalo. A la celebración 
también acudieron el entonces presidente de la Asociación Española de Banca, Rafael Termes, y el presidente del Banco Exterior, Francisco Fernández Ordoñez. La foto de familia que se publicó en los principales medios de comunicación parecía querer transmitir dos claros mensajes; uno, evidenciar qué establecimientos eran los que sostenían el sistema bancario español; y otro, ofrecer una imagen de concordia y cordialidad, y también de aparente superación de la crítica coyuntura que venía afectando al sector desde 1977. Hoy ya no se puede hablar de "siete grandes". Si hiciéramos una foto parecida a la de entonces, el número se reduciría a "dos grandes": Banco Santander y BBVA. La última operación financiera de relevancia ha sido la adquisición de uno de aquellos "siete grandes", el Banco Popular, por parte de la entidad que hoy preside Ana Patricia Botín-Sanz de Sautuola O'Shea. Su padre, Emilio Botín-Sanz de Sautuola García de los Ríos (Emilio Botín III), ya había logrado antes unificar en torno al Banco Santander a otros tres de esos "siete grandes": Banco Central, Banco Hispano Americano y Banco Español de Crédito. Su abuelo, Emilio Botín-Sanz de Sautuola López (Emilio Botín II), fue quien rompió con el entonces somnoliento ambiente económico santanderino, emprendiendo una estrategia expansiva que, en su primera etapa, se inició con la compra del Banco de Ávila en 1942 y culminó con la absorción del Banco Mercantil en 1946. Su bisabuelo, Emilio Botín López (Emilio Botín I), ocupó la presidencia de turno en 1918, y a partir de 1920 la ejerció de manera permanente, hasta su temprano fallecimiento a finales de 1923. Nacido con la modestia propia de un banco local en 1857, 160 años después el Santander controla el grupo bancario de mayor tamaño de España y el 18 del mundo en activos, con presencia en Europa y América; ya en 2013 era la entidad con la mayor red de distribución minorista del mundo occidental, que le proporcionaba casi el $70 \%$ de todos los beneficios del grupo. Cerró el ejercicio económico de 2017 con una capitalización bursátil de 88.410 millones de euros, situándose como el mayor grupo bancario de la zona euro y el decimocuarto del mundo'.

Atendiendo a este dilatado recorrido, por el que se han sucedido momentos de empuje, cierta euforia y, también, coyunturas críticas, parece oportuno preguntarse por las razones que pueden explicar cómo un modesto banco local, fundado por un grupo de comerciantes que desempeñaban su actividad en el puerto de Santander en los años centrales del siglo XIX, pudo mantenerse en el tiempo hasta, avanzado ya el siglo $\mathrm{XX}$, lograr estar en condiciones de entrar a formar parte en el selecto club de los "siete grandes" de la banca española, desde donde continuó un proceso de expansión que le ha llevado a ocupar una posición relevante dentro de las finanzas internacionales. Quienes se han ocupado de esta cuestión han centrado el foco de atención en los tiempos más recientes y en la influencia clave que sobre la cúspide directiva y el consejo de administración ha tenido la familia Botín, particularmente bajo la presidencia del padre de la actual presidenta (Guillén y Tschoegel, 2007; Kindelán, 2014). El acuerdo es practicante unánime a la hora de considerar un éxito la combativa política comercial que Emilio Botín III emprendió, alterando el equili-

\footnotetext{
${ }^{1}$ Expansión, 9 de enero de 2018.
}

brio entonces imperante en el sector de la banca privada, y que le proporcionó la confianza, preponderancia y el musculo financiero suficiente como para decidirse a acometer una sucesión de absorciones de entidades y una decidida apuesta por la expansión internacional. Sin embargo, el propósito de este texto es diferente. Consiste en atender a la anterior cuestión, sí, pero ampliando el marco temporal sobre el que centrar la atención. El estudio del desempeño de este Banco, desde sus orígenes como banco emisor hasta la llegada de Emilio Botín Il a la dirección general en 1934, permite acotar una serie de características, de rasgos muy particulares, distintos de los que la señalada perspectiva de más corto plazo ha resuelto resaltar y ponderar. Estas peculiaridades empezaron a perfilarse ya durante su etapa emisora, y se consolidaron durante el largo periodo que transcurrió entre su refundación como sociedad de crédito (1875) y la llegada de Emilio Botín Il a la señalada dirección general. Pues bien, a identificar e interpretar estas particularidades que, desde su origen, y por largo tiempo, rodeó la actividad gestora de este Banco, es a lo que se va a destinar las páginas siguientes.

No obstante, antes de acometer esta tarea, resulta pertinente responder a dos cuestiones previas. La primera, si la fundación del Banco de Santander se adelantó, o no, a una demanda de mejores servicios de intermediación y de nuevos y más ágiles medios de pago. Y la segunda, cuál es la explicación por la que este Banco fue de los pocos que no siguió el paso de la mayoría de los de su época, que se integraron dentro de la disciplina del Banco de España, desempeñando como sucursales las mismas funciones de intermediación.

\section{$-1-$}

El primero de estos dos interrogantes resulta oportuno ser planteado por cuanto que, conocido el desempeño, lleno de dificultades, que caracterizó a todo el sistema de banca emisora, muy bien pudiera llevar a pesar que en éste pudo ocurrir algo parecido a lo que Gabriel Tortella concluyó que sucedió con las compañías de los ferrocarriles que se construyeron bajo el estímulo de la prácticamente coetánea Ley General de Ferrocarriles (1855), en el sentido de que hubo una falta de respuesta de la demanda a los desplazamientos positivos de la curva de oferta. El resultado fue unos ingresos que, con mucho, no lograron cubrir siquiera los costes de construcción e, incluso, los gastos de explotación, poniendo en insalvables problemas a todo el entramado financiero que se articuló a la sombra de la construcción de esta red ferroviaria (Tortella, 1995, 3a edición: 186-191).

Hay algunos datos y claras evidencias que pueden llevar a concluir que, efectivamente, en algunas plazas no había el suficiente negocio como para justificar la creación de un banco emisor. Así, por ejemplo, en Pamplona, en los días en los que se empezó a articular la iniciativa de promover la creación de un banco de este tipo, la demanda de servicios financieros aún ocupaba un estado bastante incipiente, que lo explicaba una estructura empresarial jalonada por un considerable número de minúsculas unidades productivas, de responsabilidad jurí- 
dica ilimitada, que se caracterizaban por el escaso volumen financiero de sus iniciativas. Ya en funcionamiento, la cuantía de billetes que el Banco puso en circulación denotaba una gran tibieza en su empleo. Como explicación, la Junta de Gobierno reconoció que el uso de este medio de pago era aún desconocido para la mayoría de los habitantes.

Otro ejemplo. Hasta antes de la fundación del Banco de Vitoria (1864-1874), esta ciudad no había contado con negociantes titulados como "banqueros". Las necesidades más habituales de servicios financieros fueron, por tanto, cubiertas con la actividad que desempeñaron personas que se registraron como "corredores de letras"y por las propias compañías de comercio, que unían a su principal actividad de tránsito con géneros de todo tipo, algunas funciones de intermediación financiera, tales como giros, pequeños préstamos y la negociación de efectos comerciales. Por tanto, no debe ser causa de sorpresa la respuesta que, a instancias del Ministerio de Hacienda, ante la petición de un grupo de comerciantes y propietarios para establecer un banco de emisión, emitió el Consejo de Administración del Banco de España, señalando que renunciaba a la facultad que le otorgaba la ley de abrir una sucursal en aquella ciudad al no reunir las condiciones mercantiles necesarias para su alimento y sustento. Es más, en el informe, que en un primer momento también contó con el beneplácito del Consejo de Estado, se advertía de la multitud de peticiones que cada día tenían que estudiar, la mayor parte procedentes de núcleos que no ofrecían perspectiva alguna para su sostenimiento, así como de la situación precaria que atravesaban algunos de los ya existentes, por lo que, concluía, de persistirse en el establecimiento de nuevos bancos "habrá que lamentar en el futuro serias catástrofes que produzcan una crisis general desastrosa, como tan palpablemente se vislumbra para el porvenir". La crisis financiera que se desató a partir de 1866 demostró lo poco errado de esta premonición.

También resulta revelador lo acontecido en el Banco de San Sebastián (1862-1874). Este establecimiento dio comienzo a sus operaciones poniendo a disposición del público la mitad del límite legal de tres millones a que estaba autorizado a emitir. A comienzos del segundo ejercicio semestral esta cifra se incrementó en 250.000 pesetas; y así se mantuvo hasta finales de octubre de 1865. Con el nuevo año la emisión alcanzó los 2 millones de pesetas, cuantía que no varió hasta el fin del privilegio emisor y que representaba el $83,3 \%$ del límite legal permitido. Sin embargo, en relación a lo emitido, lo que realmente circuló permaneció dentro de unos umbrales más bien discretos, que revelarían las prevenciones del público por aceptar el billete como medio de pago, y que los gestores atribuyeron al hecho de que su uso, también en esta plaza comercial, era desconocido para la mayor parte de sus habitantes².

Debe tenerse en cuenta que, en general, dado el ámbito de influencia, fundamentalmente local, de todos estos establecimientos emisores, fueron las particulares circunstancia de cada plaza y los resultados de algunas decisiones puntuales de sus gestores lo que puede explicar que, en una comparación entre ellos, los movimientos interanuales de los saldos de las

\footnotetext{
2 Para una consulta más extensa del funcionamiento de estos bancos citados remito al lector a los capítulos correspondientes en Sudrià y Blasco-Martell, eds. (2016)
}

principales cuentas reflejen perfiles no siempre coincidentes. Parece claro que en las localidades antes nombradas la demanda de servicios financieros se movió dentro de unas dimensiones bastante modestas, que sugiere que no se descarte sin más la hipótesis de que algunas iniciativas se adelantaron a la existencia de una demanda sólida de servicios financieros. Pero no fue así en todos los casos. La vinculación entre el sector financiero y aquellos otros necesitados de sus servicios responde a un complejo tipo de interacción en la que Rondo Cameron (1974: 18) distinguió tres casos-tipo. El primero de éstos hace referencia a una situación en la que una financiación inadecuada limita y frena el desarrollo industrial y comercial; el segundo, indica el caso de unas instituciones financieras que promueven activamente nuevas oportunidades de inversión y prestan servicios de apoyo y asesoramiento a los potenciales inversores; y el tercero, se refiere a un sistema financiero permisivo que satisface por igual todas las necesidades de los prestatarios "dignos de crédito". Pues bien, fue el primero de estos tres casos-tipo indicados el que atenazaba al comercio de Santander a la altura de 1856. Con anterioridad a esta fecha, comerciantes-banqueros y prestamistas particulares eran los que habían venido sosteniendo el grueso de los servicios de intermediación entre ahorradores e inversores; unos servicios que a medida que avanzó la década de 1850 fueron mostrando evidentes signos de menor capacidad ante el nuevo empuje del que empezó a disfrutar con creciente intensidad la actividad comercial, sobre todo tras el inicio de la Guerra de Crimea (1853-1856). Este revitalizado comercio necesitaba imperiosamente dotarse de nuevos y más ágiles instrumentos de pago que los servicios convencionales de intermediación del momento cada vez estaban más lejos de poder ofrecer con fluidez. Y fue para poner remedio a este estado de cosas para lo que se reunieron la noche del 3 de marzo de 1856, en la sede del Tribunal de Comercio, los más renombrados representantes de los negocios santanderinos, cuya voluntad unánime fue la de crear un banco de emisión que acompañaría en adelante al nombre de su ciudad. El Banco de Santander representa, por tanto, un caso distinto a los mencionados anteriormente. Lo mismo puede decirse del Banco de Barcelona, de Cádiz, y de todos los que se constituyeron dentro de la antes mencionada primera gran oleada de aperturas. Todos ellos contribuyeron, dentro de sus respectivas áreas de influencia, a atender y mejorar la función de intermediación entre ahorradores e inversores. En Santander, el banco emisor facilitó medios de pago al comercio de la ciudad y atendió las necesidades de financiación del tráfico colonial.

La segunda de las cuestiones antes planteada también tiene su relevancia, pues de haber seguido el Santander el mismo camino que la mayoría del resto de bancos emisores, la historia financiera en la ciudad, y en el conjunto del país, hubiera sido otra muy distinta. Es suficientemente conocido que fueron razones de emergencia fiscal lo que terminó doblegando el espíritu moderadamente librecambista del polifacético ministro José Echegaray, que muy a su pesar terminó firmando el decreto de 19 de marzo de 1874, que establecía la circulación monetaria única y adjudicaba el monopolio de emisión de billetes al Banco de España, instando a los bancos locales a que se integraran bajo su disciplina. Con este "decreto Echegaray" 
se puso fin a la pluralidad de emisión en España. La reacción inmediata desde los órganos de gobierno de los bancos emisores locales fue de declarada oposición, que poco a poco se fue doblegando una a una, sobre todo cuando entabladas las primeras negociaciones uno de los acuerdos más atractivos fue que las acciones de cada antiguo banco emisor se intercambiaban a la par con las del Banco España, que entonces cotizaban muy por encima de su nominal. No obstante, las resistencias a llegar a un acuerdo de fusión siguieron siendo firmes en localidades como Reus, Tarragona, Barcelona, Bilbao y, también, en Santander (Castañeda, 2016). Lo que sobre este particular aconteció en esta última localidad no deja de resultar, cuanto menos, curioso. Tras muchos tiras y aflojas, los gestores del Banco de Santander terminaron llegando a un acuerdo de fusión con el Banco de España. Entre las bases aceptadas, la más atractiva era la que aseguraba un intercambio de acciones con premio, lo que, en un principio, y dado el decaído umbral de cotización del banco local por aquellas fechas, parecía una excelente propuesta. Sin embargo, por razones que se desconocen, el acuerdo no se firmó, renunciando definitivamente el Banco de Santander a fusionarse con el Banco de España. La hipótesis que pudiera explicar tal decisión sería la siguiente. La recuperación que por entonces estaba reflejando el movimiento de la cartera y la cuenta de resultados del banco santanderino pudo pesar mucho en el ánimo de sus accionistas y gestores. Esta mejoría se debía al notable incremento de la actividad portuaria de Santander como consecuencia de verse alteado los flujos comerciales en el nordeste peninsular por la guerra carlista que se desarrollaba con especial intensidad en esa parte del país. Entre los más atentos observadores de fuera y de dentro de la ciudad, también entre los políticos y militares, se creía tener la certeza de que el conflicto carlista se iba a prolongar mucho en el tiempo, lo que afectaría muy positivamente a la actividad del puerto; y ello, a su vez, tendría su reflejo inmediato en los resultados económicos y financieros del Banco. Se albergó, así, la esperanza de que la cotización de las acciones recuperaría el nivel que disfrutó en los primeros años de funcionamiento, cuando llegó incluso a situarse, por algún tiempo, por encima de las del Banco de España. De este modo, el Banco de Santander emprendió el camino hacia la liquidación y su transformación en sociedad de crédito, otorgándose la escritura social el 14 de enero de 1875.

$-11-$

A lo largo del marco cronológico aquí acotado, el Banco de Santander fue asentando una serie de atributos, de formas de comportamiento, de maneras desde las que hacer frente a los problemas, que caracterizaron y singularizaron por mucho tiempo a este establecimiento, y que explican el porqué de su longevidad y prolongado acomodo al ámbito de lo local.

El primero de estos rasgos fue la estrecha relación endogámica de sus gestores. En un país, como España, en el que el Estado liberal no impuso de manera contundente el monopolio de la coacción impersonal, los grupos egocéntricos por razones de parentesco, amistad y lealtad desempeñaron una función esencial en la organización de la vida económica y en la formación de los que ejercían las funciones de dirección económica y, también, política. La documentación protocolizada por los fedatarios públicos permite adivinar la estrecha conexión que existió en Santander entre familia, amigos y negocio. La cohesión de los más destacados hombres de negocios de la ciudad en virtud de cuidadas estrategias matrimoniales, que permitían entretejer una tupida red de relaciones de tipo clientelar a través de la que se trasmitía, además de afecto, también bienes, servicios e información, se proyectó inmediatamente a la estructura gestora del Banco. Desde sus inicios, y hasta el final del período aquí fijado, el Santander fue un banco de familias, hegemonizado en una primera época, que coincide con el "largo" siglo XIX, por los Pombo, hasta que al hilo de los profundos cambios que ocasionó la Primera Guerra Mundial fue ganando en ascendencia la familia Botín. Dentro de una estrategia comúnmente compartida de búsqueda privada del máximo beneficio, los primeros fueron representativos de un tipo de gestión más arraigada en las prácticas limitativas de la competencia, con un horizonte de negocio bancario que nunca llegó a superar el ámbito local y que, con el tiempo, ante el acelerado cambio estructural que se operó en la economía de Cantabria en los años de tránsito al siglo XX, exhibió una disposición financiera muy discreta, poco comprometida, perdiendo absoluto protagonismo en las grandes inversiones de la región.

Un personaje destacado fue Juan Pombo Conejo (18151889), mayor accionista y primer presidente del Banco. A él se debió el principal impulso que concluyó en la creación del banco emisor. Harinero, comerciante, banquero, armador y político, participó como socio fundador en las más importantes empresas que se pusieron en marcha en el Santander de la época. En el año 1872 figuraba como primer contribuyente -Industria y Comercio- de la provincia de Santander, y como segundo contribuyente territorial de la de Valladolid. Casado con Florentina Villameriel Blanco, en virtud de una cuidada estrategia matrimonial, emparentó a sus hijos con otras familias destacadas del ámbito empresarial de la región: Polanco-Bustamante, Cortiguera, del Campo-Fernández-Hontoria, Escalante, Labat, Ybarra. En una tercera generación se sumaron los López-Dóriga, Cabrero, Pérez del Molino, Botín-Sánchez Porrúa, Gutiérrez-Cedrún, Noriega, Quintana y Trueba, Gómez-Acebo (Pombo, 1999: 227-282). Su primer hijo varón, Cesar Pombo Villameriel (1842-1914), fue quien gestionó e instrumentalizó toda esta herencia inmaterial, que le proporcionó notable influencia en el Consejo de Administración del Banco, en el que estuvo presente ininterrumpidamente desde 1875 hasta su fallecimiento, ocurrido tres meses antes de desatarse la Primera Guerra Mundial. Con su defunción se cerró una larga etapa en la que este Banco, ya como sociedad de crédito, había podido todavía disfrutar de la inercia económica que significaban los modos bancarios más estrechamente identificados con el siglo XIX; y se abrió un nuevo y agitado periodo en el que el despertar del sueño decimonónico vino de la mano de otro apellido: Botín. Más y mejor adaptados a la competencia, los Botín se orientaron hacia un modelo gerencial que, presidido 
por la eficacia y el beneficio, percibió pronto la necesidad de superar los límites locales de influencia y de emprender una expansión, primero regional, y luego, tras el final de la Guerra Civil de 1936-1939, nacional; fue este un apreciable cambio de rumbo que, por razones estratégicas, no significó romper del todo con la nostalgia de la tradición mercantil decimonónica que había personificado mejor que nadie la presencia de Cesar Pombo Villameriel. Todavía, el peso y la influencia de las redes familiares, nostálgicas de la tradición mercantil, eran muy fuertes; proporcionaban acomodo y procuraban cortafuegos ante cualquier injerencia externa. Así lo supo interpretar el director de la sucursal del Banco de Bilbao en Santander en la Memoria del ejercicio de 1931:

"El Banco de Santander [...] fuertemente arraigado en la provincia, con una extensa red de sucursales, [...] su organización y trabajo conserva aún modalidades antiguas, y esta misma antigüedad le permite conservar clientela incondicional y otra relacionada con personalidades de su Consejo de Administración interesados en negocios locales y de la comarca, propios o de familias"3

Un segundo rasgo caracterizador de la gestión de este Banco durante buena parte del período considerado fue su prudencia en el diseño de la política financiera, que le permitió, por ejemplo, superar con éxito la etapa de inflexión que ocupó la década de 1860, o la acusada crisis que sucedió a la efervescente euforia financiera de comienzos de la de 1880.

Los datos contables reconstruidos llevan a concluir que el Banco de Santander, a diferencias de la mayoría de los establecimientos financieros de la época, no puso en práctica una política preferente de inversiones directas en el negocio ferroviario, concentrando el grueso de sus operaciones en las estrictamente comerciales, esto es: préstamos a corto plazo, negociación de letras y descuentos. No cayó, por tanto, en la persistente tentación de otros establecimientos de tomar recursos a corto plazo inmovilizándolos en activos de larga duración -acciones y obligaciones de empresas ferroviarias fundamentalmente-. Cierto es que, en los primeros años de actividad, se concedieron préstamos a la Compañía de Ferrocarril de Isabel II bajo la garantía de sus propios títulos, que se fueron renovando con cierta frecuencia. Con el tiempo, esta relación fue reduciéndose considerablemente; sobre todo desde la puesta en funcionamiento de las dos sociedades de crédito, el Crédito Cántabro (1861) y la Unión Mercantil (1862), que sí fueron ocupando esta función que paulatinamente fue abandonando el Banco, y que, al final, las hizo caer en una insalvable insolvencia, que en última instancia significó la apertura de expedientes de quiebra y la desaparición de ambas del escenario financiero local. Las personas que impulsaron la fundación de estas dos sociedades de crédito no eran distintas de las que estuvieron detrás de la creación del banco emisor. $\mathrm{Y}$ esto es lo paradójico, que estas mismas personas fueran las

\footnotetext{
3 Banco de Bilbao. Sucursal de Santander, Memoria del ejercicio de 1931, p. 2.
}

que asumieran niveles de riesgos muy diferentes según el tipo de establecimiento en el que se encontraban. Las marcadas diferencias de criterio inversor parecen indicar que la prudencia con la que se tomaron las decisiones en el Banco no tuvo la misma correspondencia con la practicada al frente de cada una de estas sociedades. Hubo una evidente disparidad de comportamiento en la asunción de riesgos, que en buena parte explicaría el diferente marco legislativo que las regulaba, mucho más permisivo para las sociedades de crédito, que no las obligó a establecer cinturones de protección con los que sujetarse ante un cambio de coyuntura.

Desde el punto de vista de la promoción de nuevas iniciativas, la repercusión del desastre financiero que siguió a la euforia a que dio ocasión las leyes de 1856 fue grande. Entre 1874 y 1880 solo se fundaron en todo el país dos bancos, el Cambio Mallorquín (1877) y el barcelonés Banco Hispano-CoIonial (1877). Sin embargo, en los dos años siguientes a 1880 se crearon nada menos que 42 bancos, de los que 26 se establecieron en Cataluña; el resto se constituyeron cuatro en Madrid, tres en Valencia, ocho en las Islas Baleares y uno en Segovia (Tedde, 1974: 272). El arco Mediterráneo fue, por tanto, el escenario principal de este nuevo rebrotar de las sociedades de crédito, sobre todo en la ciudad de Barcelona. En un contexto económico dominado por una Hacienda Pública deficitaria, que hacía poco atractivos los títulos de la Deuda, junto a una industria que atravesaba una difícil situación, y un sector agropecuario muy debilitado, el ahorro se fue orientando de manera frenética a través de los mercados de valores hacia los activos de empresas ferroviarias y sociedades bancarias (Castañeda y Tafunell, 2001; Hoyo Aparicio, 2007). Este afán especulativo se sustentaba, sobre todo, en los altos dividendos que tales empresas y sociedades fueron proporcionando meced a mejoras sustanciales en la explotación de unos ferrocarriles receptores de cuantiosos créditos que proporcionó, una vez más, este incrementado sector bancario. Los comienzos de los ochenta fueron años de efervescente euforia bursátil, de auténtica febre d'or, como así fue bautizado en los círculos financieros de Barcelona; una ciudad en la que la sucursal del Banco de España fue suministrando grandes sumas a crédito con garantía de valores, proporcionando el principal balón de oxígeno que permitió el exceso especulativo en esa plaza (Tafunell, 1985 y 1991). Pero a partir de 1882 las cosas cambiaron bruscamente. Las crecientes dificultades que algunos proveedores de acciones bancarias encontraron para recibir dinero sobre la garantía de sus títulos, unido a un exceso de la oferta de valores, provocó un colapso bolsístico que puso fin al periodo alcista anterior, extendiendo su depresión hasta, prácticamente, finales de la década. Este colapso, cuya causa algunos contemporáneos atribuyeron al efecto producido por la depresión bolsística de París sobre los títulos de sociedades españolas en poder de tenedores franceses, tuvo, por contra, su razón principal en la propia estructura bancaria española creada en los años frenéticos, y en los débiles cimientos que la sustentaron: unas carteras poco diversificadas y estrechamente vinculadas a la suerte que corriera, otra vez más, la explotación de los ferrocarriles. El impacto en Cataluña fue grande: en poco tiempo desaparecieron la mayoría de sus sociedades de crédito. En Madrid, la crisis financiera, aunque en líneas generales 
fue menos espectacular, se dejó notar con especial intensidad en un retroceso de la actividad de préstamos -exceptuando los hipotecarios- y en las cuentas corrientes. En Santander, las consecuencias fueron mucho menos dramáticas. Cierto es que el activo total descendió en un 4,4 \%; pero era una caída muy alejada de los guarismos que se constataron en la banca privada de Madrid, Valencia o en Cataluña. Todo parece indicar que esta crisis se circunscribió, fundamentalmente, a aquellas plazas con un elevado movimiento bolsístico y una tradición bancaria plural, lo que no fue el caso de Santander. En esta ciudad, el menor negocio bancario que, en comparación con épocas pasadas, estaba ocasionando el declinar de la actividad comercial por el puerto contribuyó, sin duda, a minimizar el impacto tanto de la intensa onda alcista como de las posteriores criticas consecuencias. Los efectos negociados siguieron siendo, a lo largo de toda la década de 1880 y primer quinquenio de la siguiente, la principal actividad del Banco. En su evolución, estuvieron muy contagiados por la desanimada trayectoria del movimiento mercantil que se gestionaba a través del puerto. Ante una coyuntura comercial tan abatida, la conducta prudente que caracterizó a los gestores en la etapa emisora, se fue tornando en actitud más bien conservadora o, si se prefiere, de marcada aversión al riesgo. El cada vez más estrecho negocio portuario a medida que fue transcurriendo el siglo XIX en su segunda mitad, sostén de la actividad económica en la ciudad y principal campo de operaciones bancarias, contagió la labor del Banco de Santander. Este fue centrando cada vez más su ocupación en la promoción y aseguramiento de títulos, paralizando prácticamente su actividad en cartera, así como primando estrategias destinadas a asegurar el pasivo, recortando, por una parte, el dinero bancario, y buscando, por otra, una mayor convergencia entre las cuentas corrientes y el encaje metálico. En estas décadas de progresivo decaimiento mercantil, se fue perfilando una estrategia deflacionista que impediría en el futuro aprovechar las nuevas áreas de negocio e inversión que abrió el repunte económico que se disfrutaría a partir de 1899. Hubo que esperar, por tanto, a la década de 1920, en que se dio comienzo a un nuevo período en la gestión del Banco, presidido entonces por Emilio Botín López, cuando se asentaron los cimientos que facilitaron una pronta expansión regional. Con la ayuda de su sucesor en el cargo, Saturnio Briz Larín, y el concurso de su hijo, Emilio BotínSanz de Sautuola y López, primero como consejero, y desde 1934 desempeñado la labor de director general, se afianzó la vocación de "banca mixta" que tímidamente había empezado a apuntarse al hilo de la "protección espontánea" que trajo la neutralidad de España durante la Primera Guerra Mundial.

Los más conspicuos hombres de negocios del Santander decimonónico se desenvolvieron dentro de una actitud que siempre osciló entre la audacia y el conservadurismo, entre el deseo de liberación y la búsqueda de una tutela bienhechora, entre la aceptación de la "mano invisible" y el socorro de la "mano auxiliadora del Estado"; un difícil y delicado equilibrio que solo se explica desde la actitud pragmática de que hacían gala estos agentes en la búsqueda de todo tipo de mecanismos que permitieran mantener la posición de sus negocios. La gestión del Banco de Santander no se escapó a esta serie de dicotomías. Es más, y este es el tercer y último rasgo caracterís- tico a ser resaltado, fue por lo general predominante el talante proteccionista, contrario a toda competencia y, por tanto, de abierta hostilidad a la posibilidad de nuevas fundaciones de bancos y a la apertura de sucursales de otros establecimientos bancarios en la ciudad.

Es desde la preeminencia de este talante como hay que entender el nerviosismo con el que se vivió la posibilidad de que la Sociedad General de Crédito Mobiliario Español se adelantara al proyecto de los "hombres del comercio de Santander" de fundar un banco de emisión. Los banqueros José Joaquín de Osma y Enrique O'Shea habían presentado en nombre de este establecimiento de crédito, al que representaban y en el que participaban como socios, autorización al Gobierno para la apertura de bancos de emisión en distintas capitales de provincia. Santander fue una de las ciudades a las que la sociedad de crédito de los Péreire codiciaba convertir en sede de uno de sus proyectados establecimientos. Interesada en la construcción de la línea del Ferrocarril del Norte, que uniría la capital de España con Valladolid, el Crédito Mobiliario consideraba el complemento lógico a esta inversión su participación financiera en la línea que uniría Alar del Rey con el puerto de Santander para el transporte de trigo y harinas castellanas. Esta solicitud ocasionó seria inquietud entre el grupo de promotores locales, que unos meses antes ya se habían adelantado enviando al Gobierno un completo expediente de solicitud, que incluía los estatutos y la formalización de la escritura social. Pese a considerar, en un principio, la posibilidad de llegar a un acuerdo con el Crédito Mobiliario, todos los esfuerzos se orientaron a ejercer diversos niveles de presión sobre el Gobierno para que resolviera a favor de la petición local. En las otras ciudades en las que el Crédito Mobiliario fijo su interés tampoco halló mucho a poyo doméstico. Como dejó escrito Ramón Santillán, rememorando este episodio, la Sociedad de Crédito Mobiliario no encontró en las localidades en las que se propuso establecer bancos el concurso que necesitaba: nadie se prestó a tomar las acciones que para estos establecimientos debían emitirse; $y$, por consiguiente, se vio en la necesidad de renunciar [a su proyecto]" (Santillán, 1865: tomo II, 101-103). El 15 de mayo de 1857 la Reina Isabel II dispuso por Real Decreto la concesión a Gerónimo Roiz de la Parra, Juan Abarca, Antonio Labat, Bonifacio Ferrer de la Vega, Antonio López-Dóriga y Agustín G. Gutierrez, como representantes del comercio de Santander, la creación de un banco de emisión "que se titulará Banco de Santander, con arreglo a lo dispuesto en la ley de 28 de enero de 1856". Las operaciones dieron comienzo el 20 de agosto de ese mismo año.

Es, asimismo, desde esta preponderante aversión a la competencia como hay que interpretar la beligerancia con la que se recibió la apertura en la ciudad de una sucursal del Banco de España. El 2 de enero de 1875, esto es, doce días antes de que se firmara la escritura social que transformaba el banco emisor en sociedad de crédito, la Sucursal abrió sus puertas al público. Llegar a ese punto no fue nada fácil, pues la presencia del Banco de España en esta ciudad era muy escasa, como también reducidísimo el número de accionistas locales. Así lo reconoció en varios escritos el comerciante Luis Gallo, corresponsal durante muchos años de este Banco en Santander, y que contaba con un gran prestigio entre los hombres de nego- 
Cuadro 1. Banco de Santander y Sucursal del Banco de España. Beneficios a repartir, 1875-1900 (en pesetas)

\begin{tabular}{|l|c|r|r|r|c|}
\hline Años & $\begin{array}{c}\text { Banco de } \\
\text { Santander }\end{array}$ & $\begin{array}{c}\text { Sucursal del Banco } \\
\text { de España }\end{array}$ & Años & $\begin{array}{c}\text { Banco de } \\
\text { Santander }\end{array}$ & $\begin{array}{c}\text { Sucursal del Banco } \\
\text { de España }\end{array}$ \\
\hline 1875 & 106.413 & 69.756 & 1888 & 141.603 & 50.061 \\
\hline 1876 & 52.942 & 43.221 & 1889 & 175.402 & - \\
\hline 1877 & 71.000 & 35.926 & 1890 & 157.510 & 58.031 \\
\hline 1878 & 88.729 & - & 1891 & 157.514 & - \\
\hline 1879 & 92.874 & 39.078 & 1892 & 157.504 & 149.085 \\
\hline 1880 & 92.928 & - & 1893 & 158.915 & 156.399 \\
\hline 1881 & 128.911 & 36.570 & 1894 & 158.502 & 156.639 \\
\hline 1882 & 111.787 & 23.528 & 1895 & 159.142 & 114.583 \\
\hline 1883 & 131.420 & 65.257 & 1896 & 122.693 & 108.654 \\
\hline 1884 & 146.540 & 45.049 & 1897 & 88.004 & 54.992 \\
\hline 1885 & 146.265 & 25.636 & 1898 & 210.742 & 21.687 \\
\hline 1886 & 146.576 & 86.561 & 1899 & 262.725 & 25.284 \\
\hline 1887 & 154.825 & 36.227 & 1900 & 350.137 & -32.446 \\
\hline
\end{tabular}

Fuente: Banco de Santander, Memoria(s); Sucursal del Banco de España en Santander, Memorias(s).

cios del Santander de la época; fue el principal artífice de que, finalmente, el Banco de España contara con una sucursal en Santander. También reconoció estas dificultades quien fuera su primer director, Manuel de la Escalera, y que justificaba por coexistir con un "banco local no fusionado" celoso de defender "intereses legítimamente creados y dignamente sostenidos". El Boletín de Comercio, en su habitual función en defensa de los intereses de la burguesía de los negocios de la ciudad, se hacía constante eco de las dificultades que por entonces tenía la Sucursal para hacer circular los billetes, insistiendo en que, por este importante motivo, Santander "necesita un establecimiento de crédito de la misma localidad, creado con recursos propios, que sirva de lazo común al comercio, a la vez que de auxiliar poderoso para las transacciones mercantiles, y de regulador del que ha venido a ser en España el monopolizador del crédito y de la circulación del papel moneda"4. En la pugna por hacerse con una mayor cuota de negocio bancario, la Sucursal, con una más débil implantación social, caminó siempre en clara desventaja a tenor de la apreciable diferencia a favor del Santander en los benéficos a repartir que fueron haciendo públicos una y otra entidad.

Las espadas entre uno y otro establecimiento siempre estuvieron el alto. La mayor tensión se alcanzó a finales de diciembre del año 1876. Unas semanas antes habían circulado ciertos rumores sobre la falta de solvencia del Banco de Santander. La alarma fue mayúscula cuando el director de la sucursal del Banco de España, Manuel de la Escalera, publicó un anuncio en el Boletín de Comercio en el que, sin disimulo, alertaba no solo de esta posibilidad, sino que, incluso, llegó a cuestionar la legalidad de la constitución del Banco de Santander como so-

\footnotetext{
${ }^{4}$ Boletín de Comercio, 27 de diciembre de 1876
}

ciedad de crédito. El impacto fue duro, llegándose a temer en algún momento por la desaparición del Banco: entre el 30 de noviembre de 1876 y el 31 de enero de 1877 el valor del balance cayó nada menos que en un 29,3 \%, y en un 35 \% el saldo de la cartera; la cuenta de ganancias y pérdidas, que ascendía el mismo 30 de noviembre a la cantidad de 129.937 pesetas, un mes después apenas llegaba a las 116.000 pesetas. Los efectos siguieron notándose en el transcurso del primer semestre del año 1877, pues, como se reflejó en la memoria correspondiente, hubo que "traer metálico sin reparar en el alto precio a que había que adquirirlo". A 5,3 millones de pesetas ascendió finalmente el total de metálico traído, por lo que hubo que pagar poco más de 143 mil pesetas en concepto de comisiones e intereses. Un año después, el Juez de Primera Instancia en Santander, Nicomedes de Urdangarín, entendió que el director de la Sucursal había obrado de mala fe, imponiéndole una pena de dos años, cuatro meses y un día de destierro a una distancia de 25 kilómetros de Santander y una multa de 1.125 pesetas 5 .

Fue, igualmente, este celo por dominar en exclusiva las actividades de intermediación financiera en la ciudad lo que explica las dilatadas negociaciones encaminadas a lograr la fusión con el Banco Mercantil durante los primeros meses en que este último establecimiento entró en funcionamiento. Durante las primeras semanas del verano de 1899 un grupo de emprendedores hombres de negocios de la ciudad dedicó sus esfuerzos a la promoción de una nueva entidad bancaria, alterando el quietismo en el que el Banco de Santander había decidido encerrarse. En el capital social de este nuevo establecimiento se aunaron fondos que procedían, unos, del tradicio-

\footnotetext{
5 Banco de Santander, Memoria presentada a la Junta de Gobierno en la General de Accionistas de 20 de julio de 1878, Imp. Y Lit. de J. M. Martínez, Santander, pp. 4-5.
} 
nal ahorro mercantil descontento con el estilo del Banco de Santander, y otros, del pujante capital colonial que buscaba acomodo en la metrópoli. Para todos sus promotores la creación de un banco mixto no solo era la oportunidad para acometer interesantes negocios financieros, sino el medio para cubrir las exigentes necesidades de recursos que la extensa lista de sus proyectos empresariales demandaba. El anuncio de la constitución del nuevo banco fue un elemento de ruptura ente la cohesionada burguesía santanderina, que observó con temor cómo una parte de sí misma se desmarcaba del hasta entonces incontestable sistema de familias sobre el que se había sustentado el entramado empresarial, para acometer un proyecto financiero en el que no cabían todos. En el Santander de fin de siglo, familia y empresa constituían un nexo demasiado profundo como para que el nuevo proyecto empresarial no significara una verdadera conmoción en el ámbito de los negocios locales. Desde el primer momento, la oposición de los accionistas del Banco Santander a esta iniciativa se tornó en la corriente generalizada de opinión en los ambientes de negocio de la ciudad. En gran número, a través de los medios de comunicación disponibles, se alzaron voces clamando contra la "concurrencia inútil" que supondría la existencia de dos entidades de crédito en Santander, hasta el punto de que mantener un único establecimiento bancario en la localidad acabó siendo compartida no solo por aquellas personas más vinculadas al Banco de Santander, sino incluso entre algunos de los promotores del nuevo banco. El recuerdo de la crisis que acompañó la segunda mitad de la década de 1860 había calado profundamente en la cultura financiera de un buen número de empresarios, por lo que, como diría uno de ellos, sería bueno "refrescar la memoria de mis congéneres [recordado aquella época] de movimientos especulativos que rebasaron los límites que la razón impone y que dieron lugar a aquella catástrofe del ferrocarril que arrasó a varias sociedades, a muchos particulares y que dejó a otros en la miseria, perdiendo la provincia de Santander más de doscientos millones de reales" ${ }^{\prime \prime}$. El Banco de Santander fue el primero en dar el primer paso a la hora de proponer la fusión de su entidad con la del nuevo establecimiento de crédito. Las conversaciones, con continuos tiras y aflojas, sucesivas rondas negociadoras, e incluso con la intervención de algún mediador de prestigio, como lo fue el comerciante y banquero Antonio Cabrero Campo, se saldaron con un sonoro fracaso. El Banco Mercantil abrió sus puertas al público el 4 de noviembre de 1899. A partir de entonces, se fue perfilando un horizonte de competencia al que no estaba acostumbrado el veterano Banco de Santander.

$-|I|-$

El objetivo de alcanzar tan pretendida hegemonía financiera en la región, que indudablemente simbolizó la absor-

\footnotetext{
${ }^{6}$ Boletín de Comercio, 29 de agosto de 1899.
}

ción del Banco Mercantil por parte del Banco de Santander, solo vino como resultado de un cambio de mentalidad y de percepción del negocio bancario, que personificó mejor que nadie Emilio Botín-Sanz de Sautuola y López (Emilio Botín II). Hombre de profundas convicciones religiosas, en una de sus contadas entrevistas concedidas a lo largo de toda su vida, se confesó como una persona, además, de talante liberal "por sentimiento, por manera de pensar y por manera de actuar"; una concepción liberal, aclararía, "naturalmente económica [dada su] mejor capacidad para hacer frente a los retos que un sistema democrático ha de plantearnos: en este sistema inexorablemente se produce la autoselección, y no hay privilegio de familia, ni de herencia, que no sea arrasado por la ley implacable del mercado libre" ${ }^{17}$.

Levantada definitivamente la moratoria para el cierre y presentación de balances por ley de 17 de octubre de 1940, el Banco de Santander celebró el 5 de marzo de 1942 la primera Junta General de Accionistas tras el inicio de la Guerra Civil, en la que el Consejo de Administración rindió cuentas de los ejercicios comprendidos entre los años 1936 y 1941. La conclusión más evidente que se desprende de la lectura de la memoria cerrada con el ejercicio de ese último año es la comprensión por parte de los gestores del Banco de las nuevas condiciones en las que el negocio del crédito comenzaba a desarrollarse a la sombra de la restrictiva política económica franquista, y que tendía a la creación de un reducido, pero poderoso, grupo de entidades. El Banco, en la persona de su director gerente Emilio Botín II, comprendió rápidamente que el camino no solo de maximización del beneficio, sino ya de la misma supervivencia como empresa, se encontraba en emprender una ambiciosa expansión, para la que no era suficiente la concertación externa con corresponsales y agentes. Con este horizonte, lo primero fue aumentar los fondos propios; una decisión que acometió de forma temprana, y que le permitió al Banco disponer de una sólida base de recursos con los que abordar la absorción de tres sociedades bancarias con un elevado interés estratégico para los proyectos de crecimiento perfilados por Emilio Botín II. Con fecha 2 de febrero de 1942 el Consejo de Ministros aprobó la absorción del Banco de Ávila; en ese mismo año se formalizó escritura de absorción de los bancos Herrero Riva y de Torrelavega. El quinquenio comprendido entre 1939 y 1944 significó, por tanto, para el Banco de Santander un primer paso para adquirir el tamaño, la estructura y la capacidad operativa adecuada con la que empezar a introducirse con ciertas garantías en el terreno de la gran banca nacional. Sin embargo, un último escollo separaba al Banco de estar en condiciones de alcanzar este objetivo final. Para ello debía hacerse con el control del mercado regional; y ello pasaba por abordar el "asalto" a su antiguo competidor: el Banco Mercantil. Como se puede constatar en los cuadros 2 y 3, esta entidad bancaria, que entonces presidía Isidoro del Campo, se había convertido, por su pasividad, en una presa muy apetecible. En el transcurso de esos primeros años de posguerra el Banco dirigido por Emilio Botín Il empezó a superarlo tanto en las más relevantes magnitudes de su activo como en la disponibilidad

\footnotetext{
7 El País, 1 de agosto de 1976.
} 
Cuadro 2. Banco Mercantil y Banco de Santander. Estructura de la inversión, 1939-1945 (.000 de pesetas)

\begin{tabular}{|c|c|c|c|c|c|c|c|}
\hline \multicolumn{8}{|c|}{ Banco Mercantil } \\
\hline & $\begin{array}{l}\text { Efectos de } \\
\text { Comercio }\end{array}$ & Créditos & $\begin{array}{l}\text { Inversión } \\
\text { comercial }\end{array}$ & $\begin{array}{l}\text { Fondos } \\
\text { públicos }\end{array}$ & $\begin{array}{l}\text { Valores in- } \\
\text { dustriales }\end{array}$ & $\begin{array}{c}\text { Cartera de } \\
\text { títulos }\end{array}$ & $\begin{array}{c}\text { Inversión } \\
\text { total }\end{array}$ \\
\hline 1939 & $13.589,0$ & $38.015,8$ & $51.604,8$ & $124.515,1$ & $20.893,7$ & $145.408,8$ & $197.013,6$ \\
\hline 1940 & $11.804,1$ & $37.765,7$ & $49.569,8$ & $159.586,1$ & $23.749,7$ & $183.335,8$ & $232.905,6$ \\
\hline 1941 & $16.834,0$ & $53.717,7$ & $70.551,7$ & $165.615,6$ & $24.463,4$ & $190.078,9$ & $260.630,5$ \\
\hline 1942 & $29.781,3$ & $72.784,9$ & $102.566,2$ & $145.604,1$ & $24.615,9$ & $170.220,0$ & $272.786,2$ \\
\hline 1943 & $31.350,6$ & $72.400,4$ & $103.751,0$ & $144.036,1$ & $23.667,6$ & $167.703,7$ & $271.454,7$ \\
\hline 1944 & $34.307,1$ & $74.045,8$ & $108.352,9$ & $173.025,6$ & $27.131,1$ & $200.156,7$ & $308.509,6$ \\
\hline 1945 & $31.645,8$ & $65.280,1$ & $96.925,9$ & $162.037,0$ & $38.604,5$ & $200.641,5$ & $297.567,4$ \\
\hline \multicolumn{8}{|c|}{ Banco de Santander } \\
\hline & $\begin{array}{l}\text { Efectos de } \\
\text { Comercio }\end{array}$ & Créditos & $\begin{array}{l}\text { Inversión } \\
\text { comercial }\end{array}$ & $\begin{array}{l}\text { Fondos } \\
\text { públicos }\end{array}$ & $\begin{array}{l}\text { Valores in- } \\
\text { dustriales }\end{array}$ & $\begin{array}{c}\text { Cartera de } \\
\text { títulos }\end{array}$ & $\begin{array}{c}\text { Inversión } \\
\text { total }\end{array}$ \\
\hline 1939 & $5.332,3$ & $32.681,0$ & $38.013,3$ & $47.378,1$ & $24.359,6$ & $71.737,7$ & $109.751,0$ \\
\hline 1940 & $5.732,7$ & $42.107,6$ & $47.840,3$ & $53.749,8$ & $35.475,9$ & $89.225,7$ & $137.066,0$ \\
\hline 1941 & $6.541,9$ & $63.771,7$ & $70.313,6$ & $61.714,5$ & $38.294,7$ & $100.009,2$ & $170.322,8$ \\
\hline 1942 & $20.311,8$ & $102.601,6$ & $122.913,4$ & $80.709,6$ & $55.843,7$ & $136.553,3$ & $259.466,7$ \\
\hline 1943 & $41.525,2$ & $96.376,2$ & $137.901,4$ & $91.247,3$ & $51.964,5$ & $143.211,8$ & $281.113,2$ \\
\hline 1944 & $33.325,7$ & $113.324,8$ & $146.650,5$ & $102.183,9$ & $59.155,8$ & $161.339,7$ & $307.990,2$ \\
\hline 1945 & $44.695,6$ & $140.956,3$ & $185.651,9$ & $140.644,9$ & $135.021,2$ & $275.666,1$ & $461.318,0$ \\
\hline
\end{tabular}

Fuente: Banco Mercantil, Memoria(s); Banco de Santander, Memoria(s).

de recursos propios y ajenos. Con fecha 28 de agosto de 1945 los presidentes de ambas entidades hicieron público la noticia de que se había firmado el convenio de fusión. El éxito de los planes expansivos concebidos por Botín dejaba al Banco de Santander en 1946 con 56 sucursales, 60 millones de capital social y un balance total de 398,5 millones de pesetas.

El 4 de marzo de 1950 Emilio Botín II alcanzó la presidencia del Banco. Sus palabras fueron entonces que "la compra de otros bancos es el único camino de expansión, y de poder llegar a ser un gran banco nacional". Así, en 1952 absorbió la Banca Hijos de Vázquez López, en 1953 hizo lo propio con el Banco Agrario de Baleares, en 1957 adquirió la totalidad de las acciones del Banco Soler y Torrá; en la década de los sesenta y setenta intensificó la política de absorciones y adquisiciones: Banco Cid, Banco Jáudenes Barcena de Vigo, Banco de Fomento de Gerona, Banco de Mataró, Banca Industrial de Barcelona, Banco Continental; ya en los ochenta, adquirió el control de Banca Jover, Banco Comercial Español, y procedentes del Grupo Rumasa, el Banco de Murcia y el Banco Comercial de Cataluña. Esta política de absorciones, unida a la apertura de sucursales y agencias urbanas, colocó en poco tiempo al Banco dentro del grupo de los llamados "siete grandes" de la banca española. Y a ello contribuyó, en no poca medida, la incursión financiera en Hispanoamérica; un ámbito de proyección hacia el que Emilio Botín II mostró un gran interés desde el mismo día en que accedió a la presidencia.

En los años 40 había emprendido una serie de viajes por los países americanos de habla hispana: "quedé impresiona- do y apenado" -diría muy posteriormente, recordando aquellos años, en un discurso que pronunció en Madrid en el año 1986- "¿cómo era posible que no hubiera bancos, sucursales y representaciones de bancos españoles en aquellas naciones, cuando desde hacía ciento veinticinco años trabajaban con éxito los de otros países?". El primer paso en dirección a cubrir este vacío fue gestionado por el propio Emilio en 1947, y consistió en la firma de un acuerdo de corresponsalía exclusiva y recíproca con el Trust Company of Cuba; una primera iniciativa a la que siguió en 1951 el establecimiento de representaciones en México, Argentina, Venezuela y, más tarde, en Buenos Aires (1964) y en Panamá (1967). De este modo, la creciente influencia del Banco de Santander en América obligó a la creación en 1955 del Departamento Iberoamericano, con el principal cometido de diseñar y gestionar la expansión americana. Fue ésta una estrategia que cobró renovados impulsos en 1965 al fundar, conjuntamente con el Bank of America, el Banco Intercontinental Español (Bankinter), y que prosiguió con fuerza en los años 70 con la adquisición del First National Bank of Puerto Rico. A comienzos de la década de los 80 el Banco de Santander ya disponía de establecimientos plenamente operativos en Santo Domingo, Costa Rica, El Salvador, Guatemala, Miami, Nassau, Sao Paulo y Uruagay, que completó con la compra del Banco Español-Chile.

En 1986, año en el que Emilio Botín II cesa en la presidencia -cargo que pasó a ser ocupado por su hijo Emilio BotínSanz de Sautuola y García de los Ríos-, el Banco contaba ya con 1.444 oficinas en España y 144 en el extranjero, disponía 
Cuadro 3. Banco Mercantil y Banco de Santander. Estructura de los recursos, 1939-1945 (.000 de pesetas)

\begin{tabular}{|c|c|c|c|c|c|}
\hline \multicolumn{6}{|c|}{ Banco Mercantil } \\
\hline & \multicolumn{3}{|c|}{ Recursos propios } & \multirow{2}{*}{$\begin{array}{l}\text { Recursos } \\
\text { ajenos }\end{array}$} & \multirow{2}{*}{$\begin{array}{l}\text { Recursos to } \\
\text { tales }\end{array}$} \\
\hline & $\begin{array}{l}\text { Capital desem- } \\
\text { bolsado }\end{array}$ & Reservas & Total & & \\
\hline 1939 & $8.400,0$ & $19.100,0$ & $27.500,0$ & $204.597,8$ & $232.097,8$ \\
\hline 1940 & $8.400,0$ & $20.000,0$ & $28.400,0$ & $219.231,6$ & $247.631,6$ \\
\hline 1941 & $8.400,0$ & $21.200,0$ & $29.600,0$ & $262.900,4$ & $292.500,4$ \\
\hline 1942 & $8.400,0$ & $22.000,0$ & $30.400,0$ & $271.088,2$ & $301.488,2$ \\
\hline 1943 & $8.400,0$ & $23.100,0$ & $31.500,0$ & $295.807,2$ & $327.307,2$ \\
\hline 1944 & $8.400,0$ & $25.000,0$ & $33.400,0$ & $334.886,4$ & $368.286,4$ \\
\hline 1945 & $8.400,0$ & $27.000,0$ & $35.400,0$ & $325.372,1$ & $360.772,1$ \\
\hline \multicolumn{6}{|c|}{ Banco de Santander } \\
\hline & \multicolumn{3}{|c|}{ Recursos propios } & \multirow{2}{*}{$\begin{array}{l}\text { Recursos } \\
\text { ajenos }\end{array}$} & \multirow{2}{*}{$\begin{array}{l}\text { Recursos to- } \\
\text { tales }\end{array}$} \\
\hline & $\begin{array}{l}\text { Capital desem- } \\
\text { bolsado }\end{array}$ & Reservas & Total & & \\
\hline 1939 & $10.000,0$ & $8.807,0$ & $18.807,0$ & $133.891,4$ & $152.698,4$ \\
\hline 1940 & $10.000,0$ & $9.098,0$ & $19.098,0$ & $130.011,1$ & $149.109,1$ \\
\hline 1941 & $12.500,0$ & $9.380,0$ & $21.880,4$ & $177.009,4$ & $198.889,4$ \\
\hline 1942 & $18.000,0$ & $10.237,0$ & $28.237,0$ & $277.724,0$ & $305.961,0$ \\
\hline 1943 & $23.250,0$ & $10.778,3$ & $34.028,3$ & $300.398,4$ & $334.426,7$ \\
\hline 1944 & $24.180,0$ & $13.097,0$ & $37.277,0$ & $373.494,6$ & $410.771,6$ \\
\hline 1945 & 40.000 .0 & $15.600,0$ & $55.600,0$ & $462.386,5$ & $517.986,5$ \\
\hline
\end{tabular}

Fuente: Banco Mercantil, Memoria(s); Banco de Santander, Memoria(s).

de 2.500 corresponsales repartidos por todo el mundo; de los 118 empleados de 1930, se había pasado a alcanzar la cifra de 9.698 solo en España; gestionaba un 7,44 \% del total de los recursos ajenos en manos de la banca española; y se hallaba instalado en un sólido quinto puesto dentro del ranking nacional de bancos, por detrás del Central, Español de Crédito, Hispano Americano y Bilbao. Un preciado fruto de todo ello, y signo de buena consideración, fue su admisión a cotizar en la Bolsa de Londres (1985) y en la de Nueva York (1987).

$-I V-$

El Banco de Santander no se adelantó a una demanda de mejores servicios de intermediación y de nuevos y más ágiles medios de pago. Ello hubiera comprometido su futuro. Todo lo contario. Con la fundación de este establecimiento lo que se pretendió fue atender mejor a las necesidades que ya había por optimizar los mecanismos de intermediación entre ahorradores e inversores, por facilitar medios de pago y por socorrer las crecientes necesidades de financiación del trafico colonial. Fue un banco del comercio y para el comercio; un banco de comerciantes y para comerciantes. En la celebración de su 50 aniversario (1907) la Junta de Gobierno de entonces recordaba en un pequeño texto que acompañó a la Memoria de ese año que la historia del Banco de Santander había sido "la del comercio de La Montaña, con la que ha estado ligado en íntimo y estrecho consorcio. (...) Su vida es la vida de la inteligente falange de comerciantes que tan altos pusieron el nombre y el crédito de esta región en el mundo de los negocios, y la de los que han ido sucediendo a aquéllos en la activa gestión de las transacciones mercantiles de la plaza".

La estrecha relación endogámica de sus gestores, con fuertes vínculos familiares y de amistad instrumental, el diseño de una política financiera que al compás del languidecimiento de la actividad portuaria a medida que fue avanzando el siglo XIX en su segunda mitad se fue tornando en conservadora, con marcada aversión al riesgo, y el talante proteccionista, contario a toda competencia, constituyen los tres principales rasgos, muy particulares de este Banco, que empezaron a perfilarse ya en sus orígenes como banco emisor. Estos atributos proporcionaron seguridad, una eficaz defensa ante posibles injerencias externas, y un prolongado acomodo del negocio al ámbito local: hasta 1923 no se abrió ninguna sucursal fuera de la ciudad de Santander.

Y ello no fue malo para el Banco: ganó dinero, y mantuvo una cota de rentabilidad bastante pareja al nivel medio ofre- 
cido por el conjunto de las empresas españolas. Si la comparación se hace con el rendimiento que proporcionó la Deuda Pública, el Banco de Santander obtuvo la mayoría de los años unos porcentajes por encima de los anotados para los valores públicos. A pesar de su pequeño tamaño, el Banco remuneró de manera generosa a sus accionistas. Salvo en muy contadas ocasiones, siempre repartió dividendos por encima del $10 \%$, llegando a veces hasta el $20 \%$, como lo fue en los años 1889 , 1890 y 1920 . Esta remuneración estaba a la altura de la que recibieron los propietarios de entidades mayores, como el Banco de Bilbao o el de Barcelona (Martín Aceña, 2007: 70). Fue una constante preocupación de las sucesivas Juntas de Gobierno distribuir buenos dividendos a los accionistas; a cambio, la fidelidad de éstos fue muy alta.

\section{Bibliografía}

CAMERON, R. (1974): La banca en las primeras etapas de la industrialización, Madrid, Tecnos.

CASTAÑEDA, LI. (2001): El Banco de España (1874-1900): la red de sucursales y los nuevos servicios financieros, Madrid, Banco de España.

CASTAÑEDA, LI. (2016): "La instauración del monopolio de emisión y la absorción de los bancos de emisión provinciales por el Banco de España", en Carles Sudrià Triay y Yolanda Blasco-Martel (eds.), La pluralidad de emisión en España, 1844-1874, Bilbao, Fundación BBVA/Fundación Bosch i Gimpera, pp. 641-656.

CASTAÑEDA, LI. y TAFUNELL, X. (2001): “La Bolsa de Barcelona entre 1849 y 1913: un nuevo índice", en Carles Sudrià y Daniel A. Tirado (eds.), Peseta y protección. Comercio exterior y crecimiento económico en la España de la Restauración, Barcelona, Edicions Universitat de Barcelona, pp. 281301.

GUILLÉN, M. F. y TSCHOEGL, A. (2007): Santander, el Banco, Madrid, LID Editorial Empresarial.

GUTIÉRREZ SEBARES, J. A. y HOYO APARICIO, A. (2007): “Finanzas con apellidos. Historia financiera del Banco de Santander, 1857-1936", Revista de la Historia de la Economía y de la Empresa, l, pp. 93-112.

HOYO APARICIO, A. (2000): “Emilio Botín-Sanz de Sautuola y López (1903 1993)", en Eugenio Torres (ed.), Los 100 empresarios españoles del siglo XX, Madrid, LID Editorial Empresarial, pp. 398-402.

HOYO APARICIO, A. (2007): Economía y mercado de valores en la España contemporánea. La evolución de la Bolsa antes del <<big bang>> español, 1831-1988, Santander, Editorial Universidad de Cantabria.

HOYO APARICIO, A. (2015): De comerciantes y para comerciantes. El Banco de Santander, 1857-1874, Santander, Editorial Universidad de Cantabria.

HOYO APARICIO, A. y GUTIÉRREZ SEBARES, J. A. (2010): "Al paso de los grandes: el Banco de Santander y la absorción del Banco Mercantil (1945-1946)", en J. Morilla et all., Homenaje a Gabriel Tortella. Las claves del desarrollo económico y social, Madrid, LID Editorial Empresarial, pp. 515-529.

KINDELÁN, J. V. (2014): Emilio Botín y el Banco de Santander. Historia de una ambición, Madrid, Conecta.

MARTíN ACEÑA, P. (2007): 1857-2007. Banco Santander, 150 años de historia, Madrid, Turner.

POMBO, P. (1999): Juan Pombo. Historia empresarial del siglo XIX, Santander, Ediciones de Librería Estudio.

SANTILLÁN, R. (1865): Memoria histórica sobre los Bancos Nacional de San Carlos, Español de San Fernando, Isabel II, nuevo de San Fernando, y de España, 2 vols., Madrid, Establecimiento Tipográfico de T. Fortanent.

SUDRIÀ, C. (2016): "La banca emisora provincial y la economía española: dinero y crédito", en Carles Sudrià Triay y Yolanda Blasco-Martel (eds.), La pluralidad de emisión en España, 1844-1874, Bilbao, Fundación BBVA/ Fundación Bosch i Gimpera, pp. 141-191.

SUDRIÀ TRIAY, C. y BLASCO-MARTEL, Y. (eds.) (2016): La pluralidad de emisión en España, 1844-1874, Bilbao, Fundación BBVA/Fundación Bosch i Gimpera.

TAFUNELL, X. (1985): "La febre d'or: auge borsari i activitat económica", L'Avenç, 78.

TAFUNELL, X. (1991): "Banca i mercat de capitals, 1866-1914", en Jordi Nadal (dir.) Història Económica de la Catalunya Contemporánea, Vol. 3, Barcelona, Grupo Enciclopèdia Catalana, pp. 379-421.

TEDDE, P. (1974): “La banca privada en España durante la Restauración, 18741914", en Gabriel Tortella (dir.), La banca española en la Restauración, Tomo I, Madrid, Servicio de Estudios del Banco de España, pp. 217-456.

TEDDE, P. (2015): El Banco de España y el Estado liberal (1847-1874), Madrid, Gadir Editorial/Banco de España.

TORTELLA, G. (1995): Los orígenes del capitalismo en España. Banca, Industria y Ferrocarriles en el siglo XIX, Madrid, Tecnos, $3^{\text {a }}$ edición. 